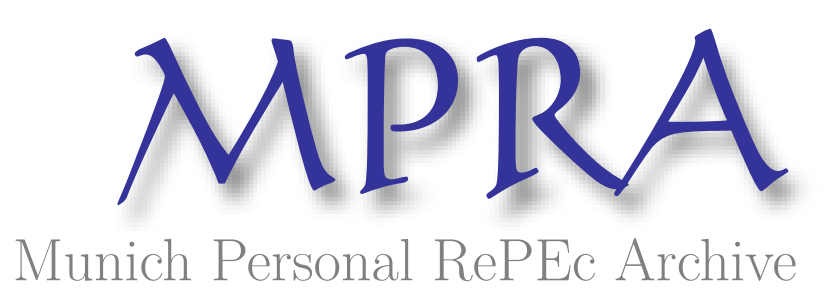

\title{
Another Look at the Deterrent Effect of Death Penalty
}

Choe, Jongmook

1 March 2009

Online at https://mpra.ub.uni-muenchen.de/14071/

MPRA Paper No. 14071, posted 14 Mar 2009 07:41 UTC 


\title{
Another Look at the Deterrent Effect of Death Penalty
}

\author{
Choe, Jongmook
}

March 1, 2009

\begin{abstract}
There is a question whether the execution rate is appropriate to examine the deterrent effect of death penalty. Instead of using execution rate, this paper uses dummy variables to categorize states into different groups and to compare the group mean homicide rates. With U.S. state-level panel data for the period 1995 - 2006, this paper fails to find a significant homicide-reducing effect of death penalty.
\end{abstract}

Keywords: Death Penalty, Execution, Homicide, Deterrence, Dummy Variable

JEL Code: K14, K42

\section{Introduction}

Recent works on the deterrent effect of death penalty show contradicting results. In most previous studies, the execution rate was used as the main determinant of the deterrent effect. (Zimmerman, 2004; Dezhbakhsh, Rubin and Shepherd, 2003; Katz, Levitt and Shustorovich, 2003; Mocan and Gittings, 2003; Mocan and Gittings, 2006). However, a couple of studies cautioned against using the execution rate in death penalty analysis. Donohue and Wolfers (2005) pointed out that the variation in number of execution among states is too small, implicating it would be very hard to extract meaningful deterrent effect (Katz, Levitt, and Shustorovich, 2003). Katz et al. (2003) also stated that only one in 300 murders was punished by death between 1976 and 1997 in Texas, which has the highest execution rate in the United States. Also, the distribution of execution is seriously skewed among states (See Figure 1). For 
the period 1995 - 2006, the total number of execution in the United States is 792, but Texas alone has executed 294 prisoners in the same period, which accounts for $37.12 \%$ of all executions. The top three states; Texas, Oklahoma (80 executions) and Virginia (74 executions), executed 448 prisoners, which is $56.57 \%$ of total execution. This percentage goes up to approximately $80 \%$ if we include the next five states. In light of these circumstances, this paper will focus on addressing the problem of using execution rate in death penalty analysis.

Figure 1. Skewness in Distribution of Executions 1995-2006

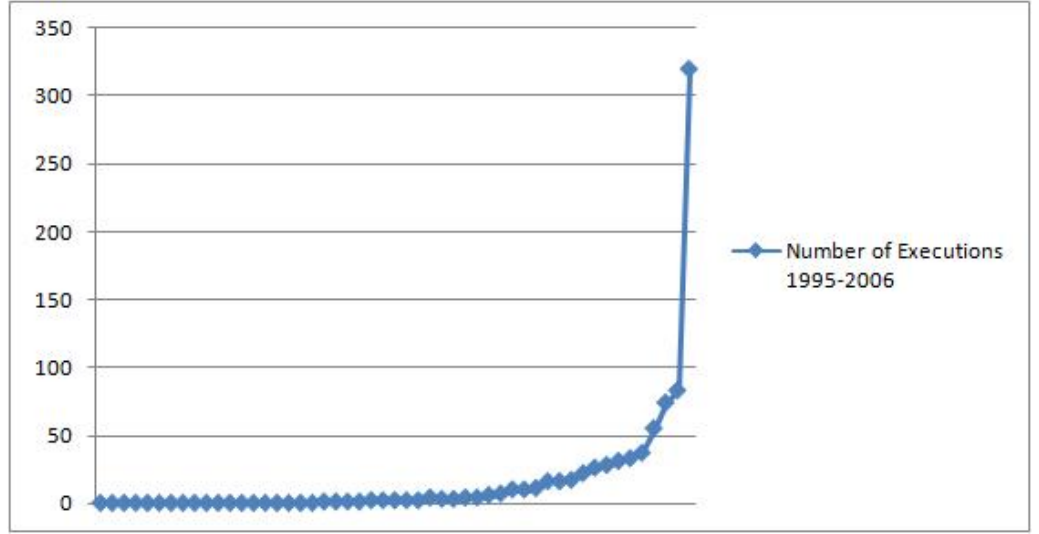

\section{$2 \quad$ Data \& Model}

This paper considers state-level panel data from the 50 states and the District of Columbia for the period of 1995 - 2006. The dependent variable is the number of homicide per 100,000 populations in each state. Without using execution rate, this paper will use one or more dummy variables which classify states into two or more categories. The estimates on dummy variable(s) measure the proportionate difference in homicide rates relative to the base group (the group without dummy variables). This method is already tried in Dezhbakhsh and Shepherd (2004), which found that death penalty law is associated with less homicide. However, these results are replicated and refuted by Donohue and Wolfers (2005).

Data on homicide are collected from the Uniform Crime Reports (UCR) produced by the Federal Bureau of Investigation (FBI). This paper also uses the following control variables: Disposable personal income per capita in constant (2000) dollars, unemployment rate, proportion of people with bachelor's degree or more in the population 25 years and over, proportion 
of people who are 18 to 24 years old, proportion of African-American people, urbanization rate and proportion of people under poverty.

However, the dummy variable method has a potential problem in our analysis. If the values of dummy variable do not change over time, we are not able to use the conventional fixed-effects model. Fixed-effects model uses the time-series information that is reflected in the changes within subjects. Since all characteristics of states that do not change over time are controlled for in a fixed-effects model, time-invariant variables will be dropped. If a variable does change over time but the magnitude of changes are very little, like a dummy variable which takes values of only 0 and 1 , fixed effects model could suffer serious inefficiency (Plümper and Troeger, 2007).

To circumvent this problem, this paper uses a fixed-effects model with vector decomposition proposed by Plümper and Troeger (2007), which suggests a three-stage procedure ${ }^{1}$ utilizing unit effects for the estimation of time-invariant variables in panel data models. Random-effects estimators use information from both within and between individual states, provided that the regressors are uncorrelated with errors, random-effects estimators are more efficient than fixed-effects estimators. In this paper, results with random-effects estimators, which retain time-invariant variables, will be reported, too. Also, System-Dynamic Panel Data estimators by Blundell and Bond (1998) uses a lagged dependent variable to account for dynamic effects. Using this method, we can control for the effects of past homicide rate on current rates. Lagged dependent variable has another advantage of being a good proxy in estimating other unobserved factors which are not captured in the model.

\section{Results (1)}

Table 1 reports panel regression results with fixed and random effects model.

\footnotetext{
${ }^{1}$ This procedure is easily executable with Stata. See http://www.polsci.org/pluemper/xtfevd.htm. For details, see Plümper and Troeger (2007).
} 
Table 1. Panel Regression Results (Fixed \& Random Effects)

\begin{tabular}{|c|c|c|c|c|c|c|}
\hline & \multicolumn{6}{|c|}{ Dependent Variable: Homicides per 100,000 population } \\
\hline & \multicolumn{2}{|c|}{ States with Death Penalty } & \multicolumn{2}{|c|}{ States with Execution } & \multicolumn{2}{|c|}{ Texas } \\
\hline & Fixed & Random & Fixed & Random & Fixed & Random \\
\hline \multirow[t]{2}{*}{ Death Penalty(1) } & $.1561^{* * * *}$ & .1187 & $.2275^{* * * *}$ & $.2036^{*}$ & $.2270^{* * * *}$ & .2050 \\
\hline & $(8.77)$ & $(.81)$ & $(12.26)$ & $(1.65)$ & $(12.16)$ & $(1.65)$ \\
\hline \multirow[t]{2}{*}{ Death Penalty $(2)$} & & & & & $.2409^{* * * *}$ & .1561 \\
\hline & & & & & $(4.38)$ & $(.96)$ \\
\hline \multirow[t]{2}{*}{ Income } & $.3756^{* * * *}$ & .2042 & $.3756^{* * * *}$ & .2808 & $.3756^{* * * *}$ & .2814 \\
\hline & $(3.67)$ & $(.74)$ & $(3.45)$ & $(1.03)$ & $(3.41)$ & $(1.03)$ \\
\hline \multirow[t]{2}{*}{ Unemployment } & .0299 & .0434 & .0299 & .0493 & .0299 & .0492 \\
\hline & $(.80)$ & $(.84)$ & $(.80)$ & $(.97)$ & $(.80)$ & $(.96)$ \\
\hline \multirow[t]{2}{*}{ Education } & .0239 & .0027 & .0239 & .0097 & .0239 & .0096 \\
\hline & $(.40)$ & $(.02)$ & $(.39)$ & $(.08)$ & $(.39)$ & $(.08)$ \\
\hline \multirow[t]{2}{*}{ Age } & $.3514^{* * * *}$ & $.4986^{* *}$ & $.3513^{* * * *}$ & $.5075^{* *}$ & $.3514^{* * * *}$ & $.5081^{* *}$ \\
\hline & $(3.86)$ & $(2.05)$ & $(3.84)$ & $(2.03)$ & $(3.80)$ & $(2.03)$ \\
\hline \multirow[t]{2}{*}{ Black } & $.3488^{* * * *}$ & $.3802^{* * * *}$ & $.3488^{* * * *}$ & $.3574^{* * * *}$ & $.3488^{* * * *}$ & $.3575^{* * * *}$ \\
\hline & $(46.21)$ & $(7.22)$ & $(42.58)$ & $(6.89)$ & $(42.37)$ & $(6.87)$ \\
\hline \multirow[t]{2}{*}{ Urbanization } & .0203 & .0193 & .0203 & .0186 & .0203 & .0187 \\
\hline & $(1.27)$ & $(1.10)$ & $(1.26)$ & $(1.04)$ & $(1.25)$ & $(1.05)$ \\
\hline \multirow[t]{2}{*}{ Poverty } & -.0575 & .0648 & -.0575 & .0799 & -.0575 & .0801 \\
\hline & $(-1.43)$ & $(.74)$ & $(-1.42)$ & $(.91)$ & $(-1.39)$ & $(.90)$ \\
\hline R-squared & .94 & .65 & .94 & .66 & .94 & .66 \\
\hline
\end{tabular}

Note: $t$ - statistics are in parentheses. Year dummies are included in all regressions.

$$
{ }^{* * * *} P<.001,{ }^{* * *} P<.01,{ }^{* *} P<.05,{ }^{*} P<.1
$$

The first column in Table 1 compares the mean homicide rates between states without death penalty and states with death penalty. Twelve states (Alaska, Hawaii, Iowa, Maine, Massachusetts, Michigan, Minnesota, North Dakota, Rhode Island, Vermont, West Virginia and Wisconsin) and the District of Columbia do not have death penalty law ${ }^{2}$. A dummy variable is set equal to one when a state has a death penalty law and zero otherwise. Since our

\footnotetext{
${ }^{2}$ New Jersey's death penalty was repealed in 2007.
} 
dummy variable is set equal to one with the death penalty law, we expect the sign of coefficient of the death penalty to be negative if death penalty had actual deterrent effect. In the second column, states without any execution record in the given period are added to states with no death penalty ${ }^{3}$. These seven states plus no death penalty states comprise de facto non-executing states.

In the United States, Texas is the leading state in terms of enforcing death penalty. As noted above, Texas alone has 294 execution records, which account for $37.12 \%$ of all executions in the United States from 1995 to 2006. In the third column, states are classified into three categories (de facto-non-executing, Texas and Others) with two dummy variables. The first dummy variable is set equal to one if the state is neither de facto non-executing nor Texas. The omitted category here is de facto non-executing, which is our base group. The second dummy variable is set equal to one if the state is Texas and zero otherwise. Therefore, the coefficient on the second dummy variable measures the following:

$$
E\{\text { Homicide } \mid \text { Texas }\}-E\{\text { Homicide } \mid \text { defactoNonExecutingStates }\}
$$

From the above results, we can see that coefficients on Death Penalty are not statistically significant or even have positive sign in some specifications, which in both cases, do not indicate deterrent effect. Donahue and Wolfers (2005) also mentions uncertainty about signs of coefficients whether it is positive or negative.

\section{Results (2) - Dynamics}

Table 2 reports regression results with a lagged crime variable using GMM estimators of Blundell and Bond (1998).

Table 2. Panel Regression Results (Dynamics)

\footnotetext{
${ }^{3}$ Seven states (Idaho, Kansas, New Hampshire, New Jersey, New York, South Dakota and Wyoming) have an active death penalty law but no execution record in the given period.
} 


\begin{tabular}{|c|c|c|c|c|}
\hline & \multicolumn{4}{|c|}{ Dependent Variable: Homicides per 100,000 population } \\
\hline & States with Death Penalty & States with Execution & Texas & Texas \& Oklahoma \\
\hline \multirow[t]{2}{*}{ Lagged Crime } & $.846^{*}$ & $.0909^{*}$ & .0876 & .0781 \\
\hline & $(1.72)$ & $(1.83)$ & $(1.77)$ & $(1.53)$ \\
\hline \multirow[t]{2}{*}{ Death Penalty(1) } & $.2422^{*}$ & .0933 & .1950 & .0799 \\
\hline & $(1.95)$ & $(.75)$ & $(1.17)$ & $(.64)$ \\
\hline \multirow[t]{2}{*}{ Death Penalty $(2)$} & & & -2.233 & -.3264 \\
\hline & & & $(-.87)$ & $(-0.73)$ \\
\hline \multirow[t]{2}{*}{ Income } & -.3237 & -.3937 & -.3329 & -.4226 \\
\hline & $(-.69)$ & $(-.84)$ & $(-.70)$ & $(-0.90)$ \\
\hline \multirow[t]{2}{*}{ Unemployment } & .0266 & .0271 & .0309 & .0313 \\
\hline & $(.38)$ & $(.39)$ & $(.44)$ & $(.45)$ \\
\hline \multirow[t]{2}{*}{ Education } & .0914 & .0580 & .0845 & .0608 \\
\hline & $(.53)$ & $(.34)$ & $(.49)$ & $(.36)$ \\
\hline \multirow[t]{2}{*}{ Age } & $.7967^{* *}$ & $.8570^{* * *}$ & $.8490^{* * *}$ & $.8832^{* * *}$ \\
\hline & $(2.52)$ & $(2.68)$ & $(2.66)$ & $(2.76)$ \\
\hline \multirow[t]{2}{*}{ Black } & $.3405^{* * * *}$ & $.3533^{* * * *}$ & $.3505^{* * * *}$ & $.3624^{* * * *}$ \\
\hline & $(10.27)$ & $(10.16)$ & $(10.05)$ & $(10.12)$ \\
\hline \multirow[t]{2}{*}{ Urbanization } & $.0431^{* *}$ & $.0421^{*}$ & $.0455^{* *}$ & $.0454^{* *}$ \\
\hline & $(1.99)$ & $(1.93)$ & $(2.06)$ & $(2.07)$ \\
\hline \multirow[t]{2}{*}{ Poverty } & .1093 & .1247 & .1196 & .1062 \\
\hline & $(.90)$ & $(1.03)$ & $(.99)$ & $(.87)$ \\
\hline
\end{tabular}

Note: $t$ - statistics are in parentheses. Year dummies are included in all regressions.

$$
{ }^{* * * *} P<.001,{ }^{* * *} P<.01,{ }^{* *} P<.05,{ }^{*} P<.1
$$

Same as Table 1, we notice that our results are far from deterrent effect. The second dummy variable in the third column, which measured equation (1), is finally showing negative coefficient but it is not statistically different from zero at $5 \%$ significance level. In the fourth column, we add Oklahoma to Texas. Oklahoma executed 80 inmates in our given period. This is second most in the United States and the same holds true even if we normalize the number of execution by dividing it with state population. Also, Oklahoma is one of the two states which executed inmates every year in our sample period. The second dummy variable in the fourth 
column measures:

E\{Homicide $\mid$ Texas\&Oklahoma $\}-E\{$ Homicide|defactoNonExecutingStates $\}$

Results from the fourth column are not different from previous ones. Magnitude of the second dummy variable is greatly reduced and is still not statistically significant. We can see that estimates on the Death Penalty variables are highly versatile. It is clear if we compare them to the persistence of other variables (Age, Black and Urbanization). For sensitivity check, apart from the basic specifications, regressions were performed with different sets of control variables. This paper still failed to find a deterrent effect on death penalty variables.

\section{Conclusion}

With state-level panel data from 1995 to 2006, this paper failed to find meaningful deterrent effect of death penalty. Regression results using dummy variables show that even the state with most execution record does not have statistically meaningful lower homicide rate than no death penalty states. This paper started from the question whether the existing data (that is, execution rate) could be sufficient and appropriate information when we analyze the deterrent effect of death penalty. This paper does not aim to find universal conclusions regarding the deterrent effect. Given our geographical unit, time period, selection of control variables and econometric techniques, we failed to find a robust deterrent effect of death penalty on homicide. This is the best we can get from this analysis.

\section{References}

Blundell, R., and S. Bond., 1998. Initial conditions and moment restrictions in dynamic panel-data models. Journal of Econometrics 87: 115-143.

Dezhbakhsh, Hashem, Paul H. Rubin and Joanna M. Shepherd, 2003, "Does Capital Punishment Have a Deterrent Effect? New Evidence from Postmoratorium Panel Data", American Law and Economics Review 5(2):344-376.

Donohue, J. and Justin Wolfers 2005, Uses and Abuses of Empirical Evidence in The 
Death Penalty Debate. 58 Stanford Law Review 791-845.

Katz, Lawrence, Steven D. Levitt and Ellen Shustorovich, 2003, "Prison Conditions, Capital Punishment, and Deterrence", American Law and Economics Review 5(2):318-343.

Mocan, H. Naci and R. Kaj Gittings, 2003, "Getting Off Death Row: Commuted Sentences and the Deterrent Effect of Capital Punishment", Journal of Law and Economics $46(2): 453-478$.

Mocan, H. Naci and R. Kaj Gittings, 2006, "The Impact of Incentives on Human Behavior: Can We Make it Disappear? The Case of the Death Penalty", NBER Working Paper 12631.

Plmper, Thomas and Troeger, Vera, 2007, Efficient Estimation of Time-Invariant and Rarely Changing Variables in Finite Sample Panel Analyses with Unit Fixed Effects, Political Analysis Vol. 15:2, 124-139.

Zimmerman, Paul R., 2004, "State Executions, Deterrence, and the Incidence of Murder", Journal of Applied Economics 7(1):163-193. 